\title{
Las crisis económicas: fuentes de oportunidades y desarrollo en el mundo de hoy ${ }^{1}$
}

\author{
Stéfano Zamagni*
}

\author{
Nivel: Ponencia \\ Recibido: 28 de mayo de 2012 \\ Aprobado: 21 de julio de 2012
}

\begin{abstract}
Resumen
Este documento, editado por el Dr. Justino Gómez de Benito, es una transcripción de la presentación del profesor Stefano Zamagni. En esta ponencia, el profesor Zamagni aborda tres cuestiones. La primera es la concepción que los economistas tienen sobre la noción de crisis. Luego, pasa a presentar el papel que juega la ética en la economía, específicamente para discernir entre las alternativas para la toma de decisiones y, finalmente, plantea la propuesta de la Economía de Comunión.

En la última parte del documento se muestran las inquietudes que se desarrollaron en la reunión, a través de preguntas de los participantes.

Palabras clave: Economía Civil, Crisis Económica, Economía de Comunión, Ética, Empresas.
\end{abstract}

\begin{abstract}
This document, edited by Dr. Justino Benito Gomez, is a transcript of the presentation by Professor Stefano Zamagni. In his lecture, Professor Zamagni addresses three issues. The first is the concept that economists have about the notion of crisis. Then he goes on presenting the role of ethics in the economy, particularly, to discern between alternatives for decision-making process and, finally, he puts forward a proposal for the Economy of Communion.

In the last part of this paper, the concerns, shown in the meeting, are developed through participants' questions.
\end{abstract}

Keywords: Civil Economy, Economic Crisis, The Economy of Communion, Ethics, Enterprises

1 Conferencia dictada en la Universidad Católica Silva Henríquez con ocasión de la ceremonia en que se le concedió la medalla Cardenal Raúl Silva Henríquez.

* Docente de Economía Política de la Facultad de Economía de la Universidad de Bolonia, Italia; profesor adjunto en la Universidad de Johns Hopkins, Estados Unidos de Norte América; en 2007 asume la presidencia de la agencia ONLUS de Milán. 


\section{Introducción}

Presentación del Sr. Álvaro Acuña, Decano de la Facultad de Ciencias Sociales Jurídicas y Económicas de la UCSH: Para la Facultad de Ciencias Sociales, Jurídicas y Económicas, es un agrado poder presentar hoy día al profesor Stefano Zamagni, al cual, el último tiempo, nos ha ligado una sintonía absoluta en los proyectos sociales que queremos construir.

El profesor Zamagni es profesor de Economía Política de la Facultad de Economía de la Universidad de Bolonia, además es profesor adjunto de la Universidad de Johns Hopkins. Luego de haber cursado estudios de Comercio y Economía en la Universidad Católica del Sacro Cuore en Milán, Italia, se especializó en la Universidad de Oxford. Sus actividades académicas y profesionales se desarrollaron en distintos ámbitos de su especialidad hasta asumir, en el año 2007, la presidencia de la agencia ONLUS de Milán, organización de tipo no gubernamental, para sociedades sin fines de lucro con utilidad social, hoy conocida como agencia para el tercer sector.

El Prof. Zamagni es Consultor del Pontificio Consejo para la Justicia y la Paz y de la Unión Mundial de Empresarios Cristianos. A partir de este año, integra la Directiva del Comité Internacional Caritas in Veritate, de la Pontificia Universidad Lateranense, para la difusión y estudios internacionales en el ámbito de la Doctrina Social de la Iglesia. Su fuerte inclinación social lo ha llevado a incursionar fuertemente en la economía civil y, junto al Prof. Luigino Bruni, de la Universidad de Sofía, a levantar una propuesta de una nueva economía, la economía de comunión, mirada que permite instalar al interior de las organizaciones, conceptos como reciprocidad, fraternidad, gratuidad. Es autor de numerosas publicaciones -que sería muy largo de enumerar hoy día- sobre economía política y civil; ha visitado nuestro país en dos oportunidades y hoy tenemos la suerte de tenerlo en nuestra Universidad. 
La Facultad de Ciencias Sociales, Jurídicas y Económicas se ha hecho el propósito de instalar en nuestra Universidad la mirada desde la economía civil y de la comunión. Hemos trabajado con el Prof. Luigino Bruni, de la Universidad de Sofía, y nos hemos encontrado con el Prof. Zamagni en Brasil, en mayo este año. Hemos estado buscando los puntos de encuentro para constituir un referente en nuestro país, para decir que sí hay una alternativa distinta, que no solamente existe hoy en día una opción o la otra: que vamos a un neoliberalismo absoluto o a un centralismo absoluto. Existe otra mirada que podría generar una relación distinta entre las personas, donde la gratuidad, la reciprocidad, la fraternidad, son los ejes centrales de la relación entre las personas.

Para nosotros, aparte de ser un agrado recibir al Prof. Zamagni, es un honor tenerlo en nuestra Universidad y agradecemos su paciencia y su siempre disposición a venir a visitarnos. Muchas gracias, profesor, por estar entre nosotros.

\section{Prof. Zamagni:}

El tema de este seminario se denomina "Las crisis económicas, fuentes de oportunidades y desarrollo". Voy a empezar por explicar que la palabra crisis, viene del griego krisis que significa transición. Estar en crisis significa estar en tránsito, entonces es importante recordar el sentido etimológico de esta palabra. Pero hay dos tipos de crisis, estoy hablando de crisis económicas y sociales, no de otras. Hay crisis que se llaman coyunturales y crisis que se llaman entrópicas, una palabra que no es muy usada y que también se puede entender como crisis sistémica o del sistema.

\section{Crisis entrópica y crisis coyuntural}

La distinción entre crisis entrópica y crisis coyuntural no tiene relación con el tamaño. Una crisis puede ser grande o pequeña, lo cual no es importante desde el punto de vista de mi exposición. Por ejemplo, la crisis del año 1929 fue una crisis de gran 
tamaño, una crisis casi mundial, pero fue una crisis coyuntural. La crisis de hoy, es una crisis mundial, de gran tamaño, pero es una crisis entrópica o sistémica. Entonces es un error que muchos economistas cometen al comparar la crisis de hoy con la de 1929. Se puede hacer desde un punto de vista cuantitativo, es verdad, pero no cualitativo, porque la naturaleza de la crisis de hoy es diferente a la del pasado.

¿Cuál es la diferencia entre los dos tipos de crisis? Es que una es coyuntural, es decir, cuando termina la transición, porque crisis significa transición, el sistema, en este caso el sistema económico y social, puede continuar como antes de la crisis. Entonces una crisis coyuntural es como un paréntesis que va a determinar consecuencias importantes, pero el sistema va a continuar.

En la crisis sistémica, al contrario, el problema es el siguiente: al final de la crisis, cuando termina la transición, el sistema tiene que cambiar. Este es el problema de hoy en día, no es por falta de responsabilidad, pero es un hecho que la gran mayoría de los economistas, desde el principio de esta crisis, han cometido un error terrible porque hasta el año pasado, se había considerado la crisis como coyuntural. Esta crisis empezó en los Estados Unidos en abril del 2007 y un año después en Europa, en el mes de septiembre, el tiempo cuando el Banco famoso Lehman Brothers fracasó. Hasta el año pasado, la mayoría de los economistas consideraban esta crisis como si fuera coyuntural, como si fuera la crisis de 1929.

Si ustedes leen en los libros, que hay muchísimos, está la comparación. Esto es un pecado porque hemos perdido tiempo, tres años perdidos. Es verdad que desde el año pasado también los economistas han cambiado el enfoque. Un hombre como Paul Krugman, americano, Premio Nobel de Economía, profesor de Economía, que escribe en el New York Times, lo ha admitido. Yo, como se dice, tengo una responsabilidad que es moral, el ser humano comete errores, pero si tú reconoces que has cometido un error, tienes la responsabilidad moral de declararlo y sólo algunos de los importantes economistas lo han hecho. 
Es importante esto porque los políticos, los gobiernos, se basan en los análisis de los economistas y si los economistas dicen -como dijeron hasta hace un año- que la crisis es coyuntural, que no hace falta cambiar algunas cosas importantes, los políticos no hicieron nada, casi nada, porque creyeron que se trataba de problemas de naturaleza coyuntural.

Es la razón por la cual, los investigadores, los profesores, tienen una responsabilidad muy importante, porque, aunque no son hombres o mujeres de gobierno, van a influir en la mentalidad de los políticos. Para explicar lo que he dicho, voy a hacer un diagrama muy sencillo, pero que es iluminador. Vamos a representar un gráfico de dos curvas, sobre este eje horizontal el tiempo y aquí la tasa de desarrollo. Esta es la curva que representa el desarrollo del conocimiento científico, ésta es la curva del conocimiento técnico, para decirlo en un inglés que todo el mundo sabe. Esta es la curva del "know to know why", que significa conocer por qué, algo sucede, algo pasa. Esta es la curva que representa el "know how", que significa conocer cómo. El "conocer cómo" está asociado a la técnica, en el sentido específico. El papel específico de la ciencia es el conocimiento del por qué.

Hasta hace un período, que se ubica con una fecha después de 1950, después de la II Guerra Mundial, la curva del, como vas a ver, del conocimiento científico, fue superior a la curva del conocimiento técnico. Pero después de la II Guerra Mundial algo ocurrió, que se ve hasta hoy, la distancia entre los dos tipos de conocimiento se va a agrandar, ésta es la causa primera de la incertidumbre, que no es lo mismo que el riesgo; el riesgo es una cosa, la incerteza es otra cosa.

Lo que pasa es que hoy en día nuestra sociedad conoce el cómo se hace, pero si tú te preguntas por qué, no hay respuestas, esto crea incertidumbre. Esta es la razón por la cual, como he dicho, la crisis de 1929 fue una crisis coyuntural -como sabemos, después de que el gran economista inglés, Keynes, produjo su obra fundamental-, se retornó como antes. Hoy es diferente. 


\section{Inquietudes e interrogantes}

Entonces las preguntas que nos vamos a hacer son las siguientes: ¿Qué cosas tenemos que cambiar? ¿Qué se debe modificar en nuestros sistemas económicos y sociales para salir de una manera razonable y definitiva de la crisis de hoy? Si es verdad, si uno no lo piensa es diferente, pero si uno acepta el principio que la crisis de hoy es una crisis sistémica, que no se puede salir de ella de una manera sencilla, como se dice, vamos a poner un poco más de regulación sobre los bancos especulativos, vamos a decir que el Banco Central Europeo tiene que ser similar al Banco Central de los Estados Unidos; son cosas importantes pero no son definitivas, porque son medidas de tipo coyuntural.

Entonces, ¿qué cosas tenemos que modificar, de ahora en adelante, para salir de una manera definitiva de la crisis? Tres cosas principales, que no son las únicas, pero según lo que pienso, son las más decisivas e importantes. Por favor, yo no quiero decir con esto que lo que se dice en los diarios no es importante, es importante, pero no es decisivo, ese es el punto. Es importante controlar los bancos como no se hizo, como no lo hicieron el año pasado, es importante regular los mercados financieros, es importante pero no es decisivo, porque la pregunta es ¿por qué esta crisis empezó?, porque no es una crisis cuya causa fue una destrucción, por ejemplo, por un terremoto, una explosión excepcional que haya producido la destrucción de las casas, de las oficinas, de las fábricas. No, es una crisis que viene del corazón del sistema, precisamente del sistema financiero.

\section{Propuestas fundamentales ante la desigualdad}

Entonces, cuáles son las tres modificaciones más fundamentales:

La primera es el problema de la desigualdad. Sabemos que desigualdad no es lo mismo que pobreza. Muchas personas confunden pobreza con desigualdad. Esto significa que hay personas que no tienen poder, dinero, para comer casi mil calorías por día 
porque sabemos lo que dicen los estudios de biología, de medicina, que nuestro cuerpo necesita al menos mil calorías diarias para sustentarse.

Si tú transformas esas mil calorías en poder, en el poder para comprar las cosas, más o menos necesitas dos dólares americanos por día. Entonces, el pobre, en sentido absoluto, es una persona que tiene menos de dos dólares americanos por día, en la media, porque hay diferencias entre un país y otro. Entonces, la pobreza significa que hay personas que no pueden comer, para usar un término.

Hoy en día en el mundo hay un poco menos de un billón de personas que son pobres, en el pasado fueron mucho más. Entonces, como se dice, hemos dado un paso adelante en esta dirección. Pero este es el punto, al mismo tiempo la desigualdad ha aumentado y va aumentar.

La desigualdad significa que la distancia entre un grupo social, el grupo que está al inicio de la escalera social, va a aumentar. En el coeficiente de Ginni -estadístico italiano, que hace mucho tiempo fue el primero que empezó una medida para medir la desigualdad, lo que se llama el coeficiente de Ginni-. Si vemos las estadísticas oficiales a nivel mundial, por ejemplo, de las Naciones Unidas, se puede ver que en los últimos treinta años el coeficiente de Ginni ha aumentado tres veces con respecto al período anterior, lo que significa que nuestros sistemas económicos de hoy son muy capaces de producir riqueza, porque la riqueza a nivel mundial es increíble. Pero, al mismo tiempo, no es capaz de garantizar la equidad de la distribución de la misma, la consecuencia es que las desigualdades van a aumentar.

Este es un problema que no sólo es de tipo moral o ético, porque el punto es que ésta es una medición para ofender también la dignidad humana, pero es también un problema de naturaleza económica porque hoy en día los mejores economistas a nivel mundial, saben y si no lo saben es porque no lo han estudiado lo suficiente, que cuando en un país la desigualdad va a superar un 
cierto nivel, lo que pasa es que el mecanismo de mercado -como lo conocemos- va, no digo a fracasar, pero sí casi a fracasar, eso significa que la distinción entre equidad y eficiencia, que fue famosa en el pasado, hoy en día no es verdad, no funciona, porque cuando hay demasiada inequidad, la eficiencia baja. Eficiencia significa la capacidad de un sistema de producir riqueza de un tipo o del otro.

La segunda consecuencia es que cuando la desigualdad ha superado aquel nivel, se genera la pérdida de la paz, más concretamente de la paz interior, de lo que se llama la cohesión social. Hoy en día hay muchísimos casos de guerra, que no son las guerras mundiales del pasado, no son guerras atómicas. Hoy en día hay ochenta y nueve guerras en diferentes países. Si ustedes ven las causas de las guerras de este tipo están siempre ligadas al elemento de la desigualdad, como lo que pasó en los meses anteriores en el África del Norte, con los países musulmanes como en Marruecos y Argelia. Esa es la causa, ligada al aumento de la desigualdad.

Entonces, no se puede decir-como en el pasado- que la desigualdad tenemos que aceptarla porque siempre existieron los ricos y los pobres. Ese razonamiento no tiene ninguna lógica, ninguna, porque lo que hace es desconocer la dinámica intrínseca de los sistemas económicos mundiales. Entonces, el primer desafío para salir de manera definitiva de esta crisis es: ¿Cómo afrontar el problema de la desigualdad? Ahora no tengo el tiempo para afrontar este problema pero una idea básica tengo que darles, y es que no se puede resolver el problema de las desigualdades en aumento, con medidas redistributivas.

Yo sé que esta es una tesis muy fuerte, pero es verdad. En el pasado fue posible. Hoy la lucha contra el aumento de la desigualdad se da en la esfera de la producción, no de la redistribución, lo que significa que tenemos que aumentar las capacidades de vida de las personas, no las condiciones de las personas. Este es un error increíble por el cual somos responsables nosotros, los economistas, porque vamos a decir que si hay pobres, tenemos 
que ayudarlos. ¿En qué sentido?, ¿dar dinero? Ésta es una vieja medida.

Tenemos que incluir en el sistema productivo lo que es la desigualdad. Esta es la medida que es posible hoy. Lo que no era ayer, ahora es posible. Yo sé que por razones de tipo retóricos o hipocresía de varios tipos, muchas personas piensan que se puede ayudar a los menos ricos, a los desiguales, con la redistribución. Es ridículo porque la redistribución puede funcionar por un corto plazo, un mes, dos meses, un año, dos años. ¿Y después?

\section{Inclusión social y democracia económica}

Segundo: ¿Cuál es la dignidad? Esta manera de redistribución va contra la dignidad de las personas. A diferencia del derecho al trabajo que, como se dice, es un derecho fundamental, el derecho de ser incluido en la sociedad, de no ser excluido. No es como que voy a poner mi mano aquí y voy a darte un poco de dinero, ésta es la vieja mentalidad.

Este es entonces el primer desafío, tenemos que buscar medidas, que sabemos que existen, para incluir tendencialmente a todo el mundo en el sistema productivo porque de otra manera todas las desigualdades van a superar el nivel crítico al final del cual hay problemas para la paz y para lograr una eficiencia mínima.

No tengo tiempo, pero vamos a ver también en mi país, Italia, lo que es un problema muy crítico. Cuando la desigualdad en Italia empezó a aumentar, al mismo tiempo la tasa de productividad del sistema económico italiano bajó, porque hay una correlación. La productividad está correlacionada empíricamente al nivel de desigualdad. Esa es la razón por la cual en Europa continental, en España, más que en Italia, hay una desigualdad increíble y la productividad baja, hay serios problemas.

El segundo desafío de los tres que he hablado, es el desafío de la democracia. La palabra, el concepto de democracia conti- 
núa aplicado en la esfera política. Este es un error fundamental porque la democracia es un valor y si es un valor tiene que ser aplicado en todas las esferas de la sociedad humana, no sólo en la esfera política, sino también en la esfera económica, porque de lo contrario vamos a continuar diciendo que democracia significa que haya elecciones libres cada cuatro o cinco años, en un sistema multipartidista. Es verdad, está la democracia política, en el sentido político, pero no es suficiente. Como ustedes saben el primero en decir esto fue un gran filósofo, Aristóteles, si leemos su libro fundamental Política. Aristóteles dice: la democracia no es sustentable, no puede durar, si no hay, en el término del lenguaje moderno, una democracia económica.

¿Qué significa democracia económica? Democracia económica significa participación en las decisiones estratégicas. Ese es el punto. De otra manera, la democracia política, que es una gran adquisición reciente, porque en Europa -no sé en Chile- la primera vez que la democracia política fue aplicada fue después de la Primera Guerra Mundial. Antes no existió, las mujeres no fueron admitidas a votar en Europa, tampoco en Inglaterra. Sólo después de la Primera Guerra Mundial fueron admitidas.

En Italia, después de la Segunda Guerra Mundial, por el fascismo, la dictadura, no estaba de acuerdo con la democracia, como sabemos. Esta es una adquisición muy importante que tenemos que agradecer a nuestros antepasados por habernos donado a nosotros la democracia política.

El desafío de hoy es extender el principio democrático a la esfera económica, lo que significa alargar la esfera de los que van a tomar decisiones. Es la razón por la cual en su última Carta Encíclica Benedicto XVI habla de poliarquía, al final de la Encíclica, el Papa dice: "tenemos que implementar un modelo a nivel internacional poliárquico". Poliárquico significa con una multiplicidad de centros de poder, de poder económico y financiero. Hoy en día no existe esta democracia, porque el poder financiero está en un pequeño club que sabemos dónde se encuentra: se encuentra en 
Amsterdam, en Rumania, cada mes ellos deciden las cosas más importantes y con un sistema como el agua que va a descender, se va a expandir, las decisiones van a ser aplicadas también a los bancos.

El principio democrático en la economía significa que las decisiones estratégicas, económicas no pueden ser tomadas por un pequeño grupo que decida por los otros. Como en política, democracia significa que cada ciudadano tiene la posibilidad de votar, por ejemplo, por el partido que quiera, más o menos la misma cosa tiene que ser verdadera en la esfera económica.

Este principio es muy importante también a nivel de la empresa, hoy se habla de Corporate Social Responsibility, que significa la Responsabilidad Social de las Empresas. ¿Qué significa? Esto significa democracia económica. Algunos pueden decir “oh, no... me han dicho que la responsabilidad social significa que no se tiene que dañar el medio ambiente". Eso no es una responsabilidad social, eso es una responsabilidad legal, no social, porque las leyes tienen que ser obedecidas, como pagar los impuestos.

Muchas personas tienen la confusión entre responsabilidad legal y responsabilidad social. El sentido propio de responsabilidad social es lo que he dicho, lo que se llama Democratic State Coulding. Esta expresión fue creada en los Estados Unidos, no en Europa. Los americanos han creado la expresión Democratic, porque algunos grupos de americanos muy inteligentes, muy responsables, han comprendido lo que he dicho en este sentido. Entonces, éste es el segundo desafío, cómo hacer prevalecer, con la gradualidad que es necesaria, una democracia económica, porque sin democracia económica a largo plazo, también la democracia política se va acabar, va a desaparecer. No podemos olvidarlo, la democracia política no se sustenta de sí misma. Aristóteles, uno de los grandes teóricos de la teoría política, ha escrito que la democracia política es un bien muy frágil, tiene que ser sustentada en la democracia económica. 


\section{Desarrollo humano integral}

El tercer desafío es lo que se llama el desarrollo humano integral, que es el título o subtítulo de la Encíclica Caritas in Veritate. Dice la Carta Encíclica, dirigida a todo el mundo, a los hermanos, lo que significa el desarrollo humano integral.

Para responder tenemos que comprender que el desarrollo humano tiene tres dimensiones: la dimensión material, todo el mundo la entiende. Lo que pasa es que entiende solo ésta, porque el desarrollo material significa producir más mercancía, más cosas, más riqueza material, lo que se llama en inglés GDP; Producto Bruto Nacional en español.

Lo que se lee cada día en los diarios, cuando se dice que Chile, me han dicho que este país crece al $6 \%$ por año, es para felicitarles; la China 9,5\%. Otro, la India 8\% y 7,5\%. Este es el crecimiento. Crecimiento significa la dimensión material del desarrollo. Eso es bueno porque la dimensión material es buena para sí misma. El problema empieza cuando es la única dimensión y se olvidan las otras dos; la dimensión socio-relacional y, la tercera, la dimensión espiritual.

Cuando se habla de desarrollo humano integral, la palabra integral significa que las tres dimensiones tienen que proceder de una manera equilibrada. ¿Cuál es el problema? Que en nuestra sociedad no existe este equilibrio. Cuando se habla de desarrollo, todo el mundo se refiere a la primera dimensión, que es la dimensión material. Este es el problema, la raíz de muchísimos problemas de nuestra sociedad.

Ahora se puede comprender por qué la dimensión material es la dimensión más cercana a nosotros. Cuando yo tengo hambre, la primera cosa que voy a buscar es un poco de pan, un bocadillo, no voy a pensar en el espíritu, no voy a pensar en la relación interpersonal. Entonces, es increíble, pero lo que pasa es que hoy en día esta actitud, como se dice, ha superado los límites naturales, entonces tenemos un modelo de desarrollo en nuestra sociedad 
que va a aumentar la dimensión material y a bajar las otras dos dimensiones. Este modelo no es sustentable.

La crisis de hoy es una consecuencia de este punto. La crisis de hoy no es sólo una crisis técnica. No las crean a las personas que dicen esto. No es verdad. Es una consecuencia de un modelo de desarrollo desequilibrado: se producen a nivel mundial demasiadas cosas y no se producen, por ejemplo, bienes relacionales. Los bienes relacionales son un concepto económico que empezó hace veinte años, antes no existía esta palabra, ni el concepto.

¿Por qué los bienes relacionales son así de importantes? Porque son el tipo de bien que nos produce la felicidad. Este es el punto, porque la felicidad no se obtiene con la mercancía. Con la mercancía se obtiene la utilidad pero nunca mezcla utilidad y felicidad. Yo sé que es nuestra culpa, de nosotros como profesores, en los libros escribimos sobre la función de utilidad, la que tiene que ser maximizada. Los estudiantes dicen que esto significa que si tú maximizas la utilidad vas a ser más feliz. Eso no es verdad, es lo contrario, porque la utilidad se refiere a la dimensión material. La felicidad está ligada a la dimensión relacional, es decir, a las relaciones humanas que se van a establecer en el lugar de trabajo, en la empresa, la sociedad, en las universidades, y en muchos otros lugares.

Entonces lo que pasa es que este modelo de desarrollo -desde sus inicios hasta hace treinta años- produjo buenos resultados. Por la razón que he mencionado antes, porque cuando hay pobreza, yo soy el primero en decir que tienen la necesidad de producir cosas, como he dicho cuando voy a África donde tienen hambre, no puedo hacer discursos de bienes relacionales, porque me dicen: dame agua, dame medicinas, dame pan, porque son bienes de la corporeidad del ser humano.

Entonces, el tercer desafío es el siguiente: ¿cómo balancear las tres dimensiones del desarrollo humano? Este es un desafío muy difícil. En la Encíclica Caritas in Veritate, el Papa lo dice, no es sencillo; es sencillo decidir o elegir si tienen que producir muchos 
más coches que otras cosas, pero balancear las tres dimensiones del desarrollo humano requiere no sólo un conocimiento técnico, en el sentido de la curva de antes, requiere de un ingreso en el discurso público de la categoría de valor.

Como sabemos, en la filosofía hay diferentes categorías de valores. Pero hay un punto en que el valor, la categoría de valor, no se puede tratar con los instrumentos de la técnica, con las técnicas de tipo matemático, estadístico, econométrico, de la ingeniería. Con estos diferentes tipos de técnicas tú puedes tratar el problema, ver la manera de tomar las mejores medidas, las más eficientes, pero cuando el problema es elegir, hacer una elección entre fines, no puedes.

Hay dos metáforas que nos ayudan a comprender la diferencia. Mis estudiantes en Bolonia -yo enseño también en una universidad americana, Johns Hopkins- lo saben porque en la primera lección que les hago cada año, empiezo exactamente con las dos metáforas. Los estudiantes la recuerdan, después de muchos años, me dicen: todavía me acuerdo. No se recuerdan de las otras cosas, pero de la metáfora se acuerdan. Ellos están contentos porque es más importante recordar la metáfora del burro de Buridán y de Hamlet de Shakespeare. El burro de Buridán -Buridán fue un filósofo francés del 1300-, pero el primero en comprender la historia del burro fue Dante de la Divina Comedia. Dante fue muy inteligente.

Buridán fue el filósofo que difundió eso. Él cuenta la historia de un burro que tenía mucha hambre, su patrón puso al burro en el establo con dos montones de heno iguales. El burro, por no decidir cuál de los dos empezaría a comer, se murió de hambre. Eso es un problema, ustedes tienen que pensar por qué nosotros más o menos somos como los burros de Buridán. Los chicos dicen que se equivocó porque es un burro, pero yo soy inteligente. No es verdad, porque muchas veces no sabemos tomar decisiones, no sabemos elegir y si no vamos a hacer una buena elección, lo que pasa es que el resultado es peor porque significa morir de hambre. 
¿Cuál es la solución al problema del burro de Buridán? ¡La técnica! Es decir, si el burro fuera un poquito racional habría estudiado la teoría económica de hoy, la dominante, no hubiera cometido este error y podría estar vivo. Entonces, el problema del burro de Buridán es un problema de elección entre medios, aunque el fin es único: el fin es comer, no morir.

Vamos a cambiar la historia, la metáfora. Hamlet de Shakespeare, él sabía cuál era el medio mejor, él tenía el cuchillo para matar al tío, él sabía, no fue como el burro, él sabía cuál era el medio mejor para matar, pero no tenía la capacidad de elegir, si era bueno o no matar al tío: "to be or not to be", "ser o no ser". ¿Qué significa la metáfora de Hamlet? Esta metáfora nos recuerda que otra vez tenemos la decisión de elegir entre fines y no entre medios.

El problema de Hamlet es el problema del fin, no del medio. Entonces, cuando tenemos que elegir entre fines, la técnica no nos ayuda. Tú no puedes resolver un problema en tu vida con la técnica, tienes que referirte a la categoría de valor, que puede ser un valor de tipo religioso, un valor de tipo laico, pero hay valores. Este es el punto.

El problema de los jóvenes de hoy no es el problema del burro de Buridán, es el problema de Hamlet, porque nuestros jóvenes saben cuáles son los medios, porque tienen recursos, de varios tipos; saben cómo hacer-Know How-, lo que pasa es que no saben cómo hacer el Know Why... el porqué uno tiene que hacer algo y no otra cosa, para elegir este fin o el otro. Entonces el problema del desarrollo humano integral significa esto y ese es el tema de esta conversación.

\section{Conclusión}

Entonces, voy a concluir, hemos entendido que el problema de la crisis de hoy es un problema mucho más serio que el de otras veces porque no es un problema sólo económico, sólo financiero. 
Si fuera sólo económico, sólo financiero, con algunas medidas se podría resolver. El problema es elegir un modelo de civilización o un modelo de desarrollo, si quiero usar esta palabra, esta es la razón por la cual los tres desafíos son muy importantes.

¿Es posible vencer los tres desafíos? Sí, es posible. No es posible vencer desafíos de tipo técnico. En el pasado si no había comida, no se podía comer. El problema hoy en día, a nivel mundial, no es la falta de bienes materiales, ustedes lo saben. Si hay personas que mueren de hambre no es porque no haya bastante producción de trigo o arroz. Hay demasiada producción.

Cada año se van a destruir toneladas de trigo. La causa es que en la Bolsa de Chicago había autorizado, hace veinte años, el Gobierno Americano, la emisión de derivados. Sabéis que son derivados sobre el precio de los alimentos fundamentales como el trigo, el arroz, el azúcar. Esa es la razón. Si tú vas a especular sobre el precio de los alimentos fundamentales, los que tienen un ingreso bajo no pueden comprarlos. Algunas personas dicen: "oh, se mueren de hambre porque no hay pan". ¿Cómo es posible decir estas cosas sin vergüenza? Hay demasiado pan, lo que pasa es que el sistema financiero lo ha hecho para obtener mucha más especulación, ha hecho lo que ya he dicho.

Entonces, los tres desafíos se pueden resolver, pero tenemos que cambiar esto, lo que significa cambiar la manera como vemos la realidad. Esto significa que vamos a hacer elección, lo que significa que tenemos que decidir por qué fin queremos vivir. $\mathrm{Si}$ uno me dice que el fin es acumular riqueza; yo digo: "te respeto" -porque tenemos que respetar a todo el mundo-, pero digo: "pobrecito", porque tú nunca serás feliz, porque la riqueza material no produce felicidad. Aristóteles fue el primero en decirlo de una manera muy clara. Es lo que las personas inteligentes dicen. Entonces, esa es la razón por la cual yo soy moderadamente optimista. Yo soy optimista por naturaleza. Me lo dicen mis nietos, tengo cuatro nietos que me dicen: "tú, abuelo, eres siempre optimista". "Sí, sí, yo soy siempre optimista", les digo, y es verdad. 
Voy a concluir con una cita de un pensamiento de San Agustín, que siempre gusta decir en estas ocasiones. San Agustín va a definir la esperanza como la virtud que tiene dos hijos: mejor aún, una hija muy linda y un hijo muy lindo. La hija se llama indignación, rabia, la que tenemos que probar cuando vemos las cosas malas que ocurren. El hijo se llama coraje: el coraje de comprender cómo se puede modificar la situación, el coraje de hacer este movimiento que significa ponernos a trabajar. Si tú sólo te indignas vas a ser como los occupayers in Wall Street de esta época; los muchos indignados que hay en España. ¿Tenéis indignados también aquí en Chile, o no? En todo el mundo los hay. Pero estar indignados no es todo. Tenemos que tener el coraje para cambiar los tiempos. Muchas gracias.

\section{Diálogo con el Dr. Zamagni:}

1. José Antonio Rosas, Vicerrector de la Universidad Miguel de Cervantes: ¿Es esa la propuesta económica de la Iglesia hoy día? ¿Es o no un modelo económico? ¿Qué diferencias tiene con la economía social de mercado? ¿Dónde se ha aplicado? ¿Se puede aplicar en Chile?

Dr. Zamagni: La primera cuestión es si la economía de comunión es el modelo oficial de la Iglesia. La respuesta es no. La Iglesia Católica siempre fue pluralista, siempre, podría ser que en algunos períodos históricos una forma va a prevalecer sobre la otra, pero el pensamiento de la Doctrina Social de la Iglesia es muy antiguo -porque la Doctrina Social de la Iglesia empezó en el siglo IV con los Padres de la Iglesia, no empezó con la Rerum Novarum como muchas personas creen-. Entonces, el pensamiento social de la Iglesia fue siempre en favor de un pluralismo, una pluralidad de formas de empresa, de estructuras sociales, etc. Porque las formas de empresa, de estructuras sociales, políticas, están ligadas a la matriz cultural de cada pueblo. Este es el punto, que es fundamental en la teología cristiana: la diversidad es un valor. La unidad de la que se habla no es uniformidad, la 
uniformidad significa todos iguales, que todos debemos hablar la misma lengua, todos tenemos que tener los mismos gustos. No es esa la pluralidad de la Iglesia, es la diversidad, porque la diversidad de los talentos es una riqueza.

Entonces la economía de comunión es una particular forma de aplicación de los principios fundamentales en la esfera económica que fue como ustedes saben de Chiara Lubich, la fundadora del movimiento de los Focolares, empezó aquí en América Latina, en Brasil, hace exactamente veinte años. Entonces, no puede ser único porque es demasiado joven, pero es un modelo de organización económica que, aunque no está muy desarrollado, va a poner en serios problemas a los profesores de economía, los más altos, porque no pueden comprender cómo es posible que estas empresas, que no son muchas, no sé el número exacto, pero funcionan, operan en el mercado, no afuera, no obtienen ningún peso del Estado, pagan los impuestos y son eficientes.

Este es el punto, el desafío es que no son, como se dice, pobres, son eficientes, son productivas. Esta es la razón por la cual la teoría económica oficial está en crisis porque, según la teoría económica oficial, si tú eres empresario, para ser eficiente tienes que obedecer a este principio, uno, dos, tres. Pero hay muchos otros modelos. Tú has mencionado la economía social de mercado, es un modelo muy particular, típico de Alemania, que, por ejemplo, en Italia nunca funcionó, aunque Italia es muy cercana a Alemania, desde un punto de vista geográfico, no funcionó.

En Italia funcionó el modelo de economía civil, la que se llama economía civil, que fue una invención en la Italia del mil setecientos, que es un modelo de hacer economía, cuyo principio básico es la reciprocidad, como ha mencionado antes el Rector en su presentación.

La idea de los economistas italianos del mil setecientos fue ésta: no se puede hacer una economía de mercado buena, si no hay espacio a la reciprocidad. La economía social de mercado 
es otro modelo. Entonces, la conclusión: cada país tiene que ser, como se dice: creer en su identidad. En Chile no pueden decir yo voy a adoptar este modelo, ustedes tienen que decidir, porque el tiempo de la dominación cultural, de la colonización cultural, está terminado. En el pasado se creyó que todo el mundo debía seguir el modelo americano. Al inicio inglés, después americano. Fue un desastre, porque cada país, cada pueblo tiene sus propias características, lo que pasa es que el modo de interpretar tiene que considerar la matriz cultural.

Esta es también la posición de la Doctrina Social de la Iglesia. Lo que dice el colega es verdad. Bretton Woods 1944, es el año de Bretton Woods. Hoy en día muchas personas dicen: "tenemos que ir a un nuevo Bretton Woods", para afrontar el desafío del cual yo también he hablado, pero lo que pasa es que los países que se llaman $B R I C^{2}$ no lo quieren. En el último Summit de G20, en Francia, hace tres semanas, no decidieron nada, porque los países emergentes dijeron: "No, nosotros estamos cansados de obedecerlos a ustedes". Ustedes significa: Estados Unidos, Inglaterra, Alemania, Francia, Italia, seis o siete países.

Nosotros tenemos la capacidad de inventar, esta es la razón por la cual no se puede ir a un nuevo Bretton Woods, porque si no hay mayoría en los veinte, no se puede hacer. Ese es el punto.

2. Oscar González, Director de la Escuela de Administración y Economía, UCSH. Usted podría abordar el agotamiento del modelo económico de la Unión Europea.

Dr. Zamagni: Lo que se ha dicho de la Unión Europea, es verdad. Vamos a preguntarnos: ¿Por qué la Unión Europea, que empezó en la cabeza de los actos de algunos que se llamaban Adenauer; Gasperi, italiano; Schuman, francés; y otros, todos fueron católicos, pero católicos verdaderos, no católicos de palabra? Lo que pasa es que se murieron, también los católicos se murieron,

2 BRIC significa, Brasil, Rusia, India y China, los países emergentes. 
también las buenas personas se van a morir, desafortunadamente, lamentablemente.

Es verdad que, después del principio, la Unión Europea no existe desde un punto de vista político. Es una unión comercial y monetaria, que en sí misma es buena cosa, pero no suficiente. No es necesario ser economista para comprender que la unión monetaria y la unión comercial, si no es sustentable, sostenida de una unión política, lo que significa de una unión fiscal, no puede funcionar. Este fue el error, pero como se dice, los gobernadores de nuestros países en los últimos veinticinco años creyeron que no era verdad, ahora vamos a pagar las consecuencias. Es la razón por la cual, por ejemplo, ustedes seguramente no lo saben, porque es una información típicamente europea; pero la Conferencia Episcopal de Europa, que es la Confederación de las Conferencias Episcopales de los países europeos, recientemente ha publicado un documento, donde dicen: tenemos que resolver el problema de Hamlet, no el problema del burro de Buridán. Siempre hablando de medidas, de técnicas y no de valor, tenemos que decidir cuál tipo de Europa queremos, cuál es el sistema de valores, no es suficiente hablar del intercambio de mercancías.

3. Pablo Concha, estudiante de Sociología. A mí me gustaría que desarrollara más el análisis del individuo en interacción, en una estructura social, frente a valores socio-históricos y la multiculturalidad de valores que hay dentro de la sociedad.

Dr. Zamagni: La última pregunta de nuestro estudiante de Sociología es una pregunta importante, particularmente yo sé que en esta parte del mundo, de América Latina, la Escuela Estructuralista de Sociología y también de Economía es mucho más desarrollada, mucho más que en Europa. Un estudiante como tú, nunca habría hecho hoy en día esta pregunta. ¿Por qué? Por lo que he dicho antes, hay diferentes cuadros conceptuales, pero tu pregunta es importante. ¿Cómo el individuo se va a relacionar con la estructura existente, estructuras financieras, sociales, del trabajo, diferentes tipos de estructuras? 
Mi respuesta es muy sencilla: no se puede. Si tú hablas de individuo, tú tienes que hablar de personas. El individualismo no se puede casar con las estructuras, porque el problema de hoy es que hay demasiado individualismo, tenemos que marchar hacia el personalismo.

¿Cuál es la diferencia entre persona e individuo? La persona es un individuo que está ontológicamente relacionado a otros; el individuo es lo que Leibniz, en la Mónada, hablaba: que individuo, es una palabra latina, significa que uno está solo. Los griegos llamaban al individuo idiotez. ¿Sabes qué significa idiotez? En griego significa que uno solo se ve a sí mismo. ¿Qué significa un individualista? Que no es capaz de relacionarse con otros. Entonces no puede modificar la estructura, porque entre las personas y las estructuras hay una relación que se llama mutual causality, causalidad mutua, porque las personas modifican las estructuras, y las estructuras existente van a modificar el comportamiento, pero no es que las estructuras vengan del cielo, las estructuras son un fruto de la acción de las personas que viven en sociedad.

Cuando me dicen las estructuras, yo pregunto: ¿cuándo fue creada esta estructura? ¿Por qué ustedes no lo han modificado? Algunas personas dicen: "si voy a hacer algo no es mi culpa, la culpa es de la estructura". No, no, eso es una vergüenza, decir esto, porque no es verdad y la verdad tiene que ser declarada, porque las estructuras son el producto de la acción de las personas. Si las personas son malas, van a producir estructuras malas y cuando las estructuras son normales van a condicionar, eso es verdad, pero siempre es posible modificar las estructuras.

Si vamos a estudiar la historia social y económica, tenemos muchos ejemplos, como cuando los franciscanos crearon la estructura financiera. Ellos la crearon, en el mil trescientos, porque los primeros bancos fueron todos franciscanos. Este es el punto y ¿por qué crearon estas estructuras? Porque los franciscanos son muy buenas personas. San Francisco de Asís fue bueno e inteligente, las dos cosas. Él tomó la primera medida para combatir 
la usura, crearon el asunto, Montes de Piedad, no cayeron del cielo, fueron creadas por personas que no fueron individualistas. Entonces, si queremos modificar las estructuras, tiene que cambiar la palabra individuo, porque el individuo es un egoísta, es un idiota y si uno es idiota no puede cambiar la estructura. Esa es la razón por la cual la filosofía personalista da a conocer en el mundo, hoy en día, una nueva reanudación, un reinicio, porque muchos han comprendido que un exceso de individualismo va a dar demasiado poder a las estructuras. Pero yo comprendo que tu pregunta es muy importante, tiene el mérito de una atención más grande de lo que he dicho en dos minutos.

4. Carlos Candianni, docente de la Escuela de Administración y Economía: ¿Cómo dentro de la economía de la comunión se puede resolver este problema de centrarse en el largo plazo o centrarse en el corto plazo?, y ¿cuáles son los instrumentos de política económica que tendría la economía de la comunión para poder resolverlos?

\section{Dr. Zamagni:}

El colega me ha preguntado correctamente: la economía neoclásica es una economía de largo plazo, centrada sobre largo plazo que hizo la economía keynesiana que es de corto plazo, es una distinción muy importante. Lo que pasa es que la diferencia esencial es que para la teoría neoclásica no existe -lo que ha dicho el estudiante anteriormente- una influencia de las estructuras por sobre la decisión individual. Esta es la cuna fundamental de la teoría de la economía neoclásica, porque está fundada sobre, nunca olvidar, el utilitarismo como filosofía. Es una teoría ética de filosofía moral, que Jeremy Bentham, en el año 1789, publicó en su obra fundamental. Entonces, si uno es utilitarista considera que la influencia de las estructuras no es importante. Esto no es verdad, es un error, motivo por el cual hoy la teoría neoclásica está en crisis.

En los últimos 10, 15 años, muchos neoclásicos han cambiado, por ejemplo Stigler y Krugman, que fue un neoclásico muy 
importante. Hoy en día, Amartya Sen, nunca fue neoclásico, pero ha escrito sobre el tema. Voy a citar Premios Nobel, para indicar personas influyentes. El punto es que, como sabemos hoy en día, la economía es una ciencia moral. Si vas a Cambridge, Inglaterra, a la Facultad de la Universidad, hay un panel donde están las diversas materias de economía que están bajo las ciencias morales, lo que significa que cuando los economistas van a separar la economía de la moral o de la ética van a fracasar. Muchas personas confunden la economía con la técnica económica, que significa los cálculos. Estos son instrumentos económicos para hacer los razonamientos.

Las categorías del discurso económico son básicamente morales, esa es la razón por la cual tú puedes ver un economista que puede estar técnicamente muy bien preparado, pero no es capaz de hacer un discurso. Es como el burro de Buridán, que conoce el instrumento, pero no conoce el fin para el cual el instrumento tiene que ser utilizado.

5. Rodrigo Hernández, Licenciado en Ciencias Políticas de la Universidad de Chile: Así como en Europa, en Chile también hay indignados, quizás por distintos motivos, pero indignados al fin y al cabo. Esto genera pérdida de paz social y una solución al tercer desafío sería una reforma tributaria, puesto que con esto se tendría los mismos niveles de productividad, pero como externalidad se solucionaría en parte la dimensión socio-relacional y espiritual.

\section{Dr. Zamagni:}

La otra pregunta es cómo reducir las desigualdades y dialogar con la economía de comunión. El punto es el siguiente, he dicho que la reducción de la desigualdad no se puede obtener con la sencilla redistribución. Con ello se puede reducir, en un corto plazo, la desigualdad, pero no de una manera sustentable. Un modo de respuesta consiste en ofrecer, a los que están abajo en la escalera social, la posibilidad concreta de trabajar: ese es el punto. 
Yo ahora no tengo tiempo para demostrar completamente mi sección, me limito a enunciarla. El sector capitalista de la economía, hoy en día, no puede dar trabajo a más del 75\% de la fuerza laboral, no puede. En algunos países sí, pero si se hace un promedio en Europa y norte de América. La razón está ligada al fenómeno de la globalización, a la tercera revolución industrial.

Entonces, si ustedes quieren dar trabajo a todo el mundo, no pueden pensar en el sector capitalista, en el sector de las empresas con fines de lucro para resolver el problema. Este es el error que muchos capitalistas continúan haciendo: no ven la realidad, están demasiado concentrados en el estudio de cosas abstractas, porque no van hablar con las personas, a conocerlas.

En Italia, la capitalización de las empresas que pueden ofrecer trabajo a las personas, en especial, a jóvenes, tenemos que prolongar, alargar el mercado del trabajo; junto a las empresas capitalistas, tenemos que hacer empresas sociales, se llaman así, empresas civiles, empresas de economía de comunión, empresas que trabajen sin fines de lucro.

Los gobiernos tienen que comprender esto. En Chile no lo comprenden, este es el punto. Tampoco en Italia, pero en Italia algo se puede hacer porque el país que hizo la primera Ley Nacional sobre las Cooperativas Sociales y Empresas Sociales fue Italia. Ahora van a copiar nuestra ley y nosotros estamos contentos, pero aquí, en este país, no hay. Hay ley por el voluntariado, pero el voluntariado es otra cosa. Yo estoy hablando de empresas productivas que dan trabajo, porque si somos una asociación de voluntarios se trabaja en el sentido de algo no remunerado. Yo estoy hablando de empresas que tienen un fin que es diferente del fin lucrativo, porque las empresas lucrativas no pueden dar trabajo a más de un 70-75\%, y ¿qué vamos a hacer del $25 \%$ restante? Vamos a tener desempleados por uno o dos años, después vas a trabajar algunos meses, o van a dar, como se dice, donaciones. No es posible esto, no es sustentable, es una vergüenza. 
Entonces vamos a multiplicar. Tenemos que tener nuestros gobernadores, parlamentarios, promotores de esta forma.

Pero, ¿por qué las personas no pueden ser libres?, ¿cuál es el principio de la libertad? Entonces comprenden lo que significa democracia económica. Esto, que si alguno de nosotros quiere hacer una empresa para trabajar, con las personas con síndrome de Down. En Italia todos los Down trabajan porque existen cooperativas sociales. Nello Gargiullo es italiano, puede confirmarlo. Son cooperativas sociales que van a contratar Down, son perfectos, en mi opinión son los mejores, porque son simpáticos, son muy atentos, tú tienes que enseñarles pero una vez que aprenden, lo repiten y producen, producen cosas que se van a vender.

La empresa capitalista dice: "tú eres Down, no puedo ocuparte porque hay una competencia global". Entonces, si uno es discapacitado, uno es ciego, pero los ciegos pueden producir, como un estudiante que tuve, Máximo Morelli, que es ciego y ahora es profesor de la Universidad de Columbia en New York, profesor de Economía. Él es ciego, es un economista matemático, tú le das una ecuación y él te va a decir: "mi tesis es..." No sé cómo lo hace. Es casado, tiene un hijo, antes de casarse, me decía: "profesor, te gusta mi novia." Y yo le decía: "pero tú, ¿cómo lo haces para saber si es linda?". "Profesor, no te preocupes porque yo tengo mis métodos." Él es profesor y cuando se graduó escribió la tesis conmigo. Los demás decían: "ahora no puede continuar". Y yo les decía: “¿Por qué no puede continuar?, ¿Por que es ciego no puede hacer investigación?" Y ahora es profesor en la Universidad de Columbia.

Este es el punto, que la democracia económica significa que tienen que haber distintos tipos de empresas: las empresas capitalistas son importantes para el 75\%. Entonces, si queremos combatir la desigualdad en este país, habría que pedirle al Presidente o a vuestros parlamentarios de promover leyes -como se hace ahora en Europa- para admitir empresas no capitalistas. No como los Estados Unidos, porque ustedes dependen dema- 
siado de los Estados Unidos desde un punto de vista cultural, porque en los Estados Unidos no es posible, porque son así, tiene que haber paciencia, porque para un americano empresa significa empresa capitalista. Yo les digo: ¿Dónde está escrito?... ¿En el Evangelio? ¿Está escrito en la Biblia? No, lo hemos dicho nosotros. Eso se llama imperialismo, imperialismo cultural, pero yo voy por la pluralidad.

Entonces no sigan a los Estados Unidos porque no es una buena escuela, porque los Estados Unidos es la segunda vez que han producido una crisis mundial. La primera vez fue en el veinte y nueve, ahora también en los Estados Unidos. Ellos no tienen la capacidad de enseñar a los otros, pero no son los únicos. Entonces a dialogar, a discutir, pero no seguirlos de esta manera como si fuera el Evangelio, porque ellos no tienen la capacidad de comprender que la empresa no es la misma cosa que la empresa capitalista. La única manera para combatir la desigualdad es, lo he dicho dos veces, admitir a personas lo suficientemente capaces porque hay también personas que no pueden caminar, porque tiene una discapacidad, pero no por eso vamos a dejarla fuera del proceso económico. Esto es increíble, este es el punto de la fraternidad. Hay que ver si uno tiene la mentalidad fraterna o solidaria. La mentalidad solidaria dice: si tú eres discapacitado aquí voy a darte este dinero. La fraternidad dice: tú eres mi hermano, mi hermana, yo voy a probar una medida para insertarte dentro del proceso económico. Esta es la gran diferencia.

La última pregunta la he respondido más o menos de esta manera, pero ya estamos en el tiempo. Muchas gracias. 